\title{
Sexually Dimorphic Activation of Galanin Neurones in the Ferret's Dorsomedial Preoptic Area/Anterior Hypothalamus after Mating
}

\author{
J. Bakker, S. K. Woodley, K. R. Kelliher and M. J. Baum \\ Department of Biology, Boston University, Boston MA, USA. \\ Key words: Fos, galanin, preoptic area, sexual behaviour.
}

\begin{abstract}
Male ferrets in breeding condition possess three times as many galanin-immunoreactive (IR) neurones as oestrous females in the sexually dimorphic dorsomedial preoptic area/anterior hypothalamus (dmPOA/AH). Using Fos-IR as a marker of activation, we investigated whether mating with intromission differentially activates this sexually dimorphic group of galanin-IR neurones in male and female ferrets. Male ferrets that intromitted had a significantly greater percentage of galanin-IR neurones in the dmPOA/AH that were colabelled with nuclear Fos-IR than oestrous females that received an intromission. Intromissive stimulation augmented Fos-IR in an equal percentage of galanin-IR neurones in both sexes in the medial amygdala (MA) and bed nucleus of the stria terminalis (BNST). Peripheral anosmia induced by bilateral occlusion of males' nares did not reduce the mating-induced activation of galanin-IR neurones in the $\mathrm{dmPOA} / \mathrm{AH}$, and there was a significant correlation among individual males between intromission duration and the percentage of $\mathrm{dmPOA} / \mathrm{AH}$ galanin-IR neurones colabelled with Fos-IR. Exposure of castrated, testosterone propionate-treated male ferrets to either soiled bedding or to volatile odours from oestrous females failed to induce nuclear Fos-IR in galanin-IR neurones located in the dmPOA/AH, BNST or MA, suggesting that the mating-induced activation of galanin-IR forebrain neurones in male ferrets depends more on genital-somatosensory than on olfactory inputs. The observed sex dimorphism in the mating-induced activation of galanin-IR neurones in the $\mathrm{dmPOA} / \mathrm{AH}$ raises the possibility that these neurones perform a mating-dependent function that occurs only in males.
\end{abstract}

The male ferret's dorsomedial preoptic area/anterior hypothalamus (dmPOA/AH) contains a cluster of large, Nisslstained cells that is completely absent in females $(1,2)$. The formation of this sexually dimorphic male nucleus results from the prenatal action of oestradiol formed from testosterone by local aromatization (1). Lesion studies $(3,4)$ have linked the presence of the male nucleus in the male ferret's dmPOA/AH to their motivation to approach an oestrous female as sexual partner. Thus, excitotoxic (3) or electrolytic (4) lesions centred in the dmPOA/AH of castrated, oestradiol benzoate-treated male ferrets caused them to approach a stimulus male instead of an oestrous female in T-maze tests. This lesion-induced profile of sexual partner preference resembled the partner preference of groups of ovariectomized, oestradiol benzoate-treated females that had received either sham operations or lesions of the dmPOA/AH. Lesions of the dmPOA/AH of male ferrets also disrupted the display of male coital behaviours, including neck-grips, mounts and intromissions, when paired with an oestrous female $(3,5)$.

Using immunocytochemical methods, the neurochemical phenotype of neurones in the ferret's sexually dimorphic dmPOA/AH was determined (6). A striking sex difference was found in the distribution of galanin-immunoreactive (IR) neurones: gonadally intact males in breeding condition had many more galanin-IR neurones in the dmPOA/AH than gonadally intact, oestrous females. By contrast, no sex differences were found in the number of galanin-IR neurones in other forebrain regions, including the bed nucleus of the stria

Correspondence to: Dr Julie Bakker, Center for Cellular and Molecular Neurobiology, Research Group in Behavioural Neuroendocrinology, Université de Liège, 17 Place Delcour Bat L1, Liège B4020, Belgium (e-mail: jbakker@ulg.ac.be). 
terminalis (BNST), medial amygdala (MA) and ventrolateral hypothalamus (VLH). The sex difference in galanin-IR in the dmPOA/AH did not result from sex differences in circulating testosterone levels; treatment with high doses of testosterone propionate $(5 \mathrm{mg} / \mathrm{kg})$ failed to augment the number of galanin-IR neurones in adult, ovo-hysterectomized females. However, prenatal treatment with testosterone propionate significantly increased numbers of galanin-IR neurones in the dmPOA/AH of females up to the level seen in males, implying that the capacity of these $\mathrm{dmPOA} / \mathrm{AH}$ cells to express galanin is sexually differentiated prenatally by testosterone and/or its oestrogenic metabolite in male ferrets (6). Sex differences in the distribution of galanin neurones in the $\mathrm{POA} / \mathrm{AH}$ have also been described for several other species, including the teleost fish sailfin molly (7), the goldfish (8), the mouse (9), the rat (10) and the gerbil (11).

We investigated the functional relevance of this sex difference in dmPOA/AH galanin neurones. There is evidence that galanin has both facilitating $(12,13)$ and inhibiting $(14,15)$ effects on male coital behaviour in rodent species. A recent study (16) in the ferret suggested that galanin facilitates appetitive but not consummatory aspects of sexual behaviour. Breeding male and female ferrets receiving intracerebroventricular (i.c.v.) infusions of the galanin receptor antagonist M-40 showed a diminished partner preference for the opposite sex. It is unclear, however, whether these behavioural effects were mediated by galanin neurones located in the dmPOA/AH. The present study was conducted to determine whether the sexually dimorphic population of galanin neurones in the dmPOA/AH is differentially activated by mating-associated stimuli in male as opposed to female ferrets. We compared the expression of Fos-IR, used as a marker for neuronal activity, in the nuclei of galanin-IR neurones in the dmPOA/AH with that of other nondimorphic galanin populations in the BNST and MA of mated pairs of breeding ferrets. We also determined which sensory stimuli associated with intromission in male ferrets mediate the activation of galanin neurones in the $\mathrm{dmPOA} / \mathrm{AH}$. In a second experiment, we investigated the expression of Fos-IR in the nuclei of galanin-IR neurones in the dmPOA/AH, BNST and MA of mated males in which both nares were occluded (naresoccluded males) or were left open (sham-occluded males). In a final experiment, we investigated the expression of Fos-IR in the nuclei of galanin-IR neurones in the $\mathrm{dmPOA} / \mathrm{AH}$, BNST and MA of males exposed to volatile odours or soiled bedding from an oestrous female.

\section{Materials and methods}

Animals

Gonadally intact, European male and female ferrets were purchased from Marshall Farms (North Rose, NY, USA). Subjects were housed individually in modified rabbit cages under a long day photoperiod ( $16 \mathrm{~h}$ of light, $8 \mathrm{~h}$ of darkness; lights on at $07.00 \mathrm{~h}$ ). All ferrets were fed moistened Purina ferret chow (Ralston Purina Co., St Louis, MO, USA) once a day. Water was available ad libitum. For these experiments, we wanted to use animals that were maximally responsive to sensory stimuli associated with sexual behaviour. Previous studies have shown that gonadally intact oestrous females have uniformly high levels of vulval swelling and behavioural receptivity (17) as well as maximal Fos-IR responsiveness in mediobasal hypothalamic gonadotropin releasing hormone $(\mathrm{GnRH})$ neurones (18). Therefore, all of the female subjects used in these experiments were gonadally intact and in oestrus. Among gonadally intact, breeding male ferrets, there is considerable variation in levels of coital performance. In order to ensure that the male ferrets used in these experiments showed maximal levels of coital behaviour, all were castrated under ketamine $(35 \mathrm{mg} / \mathrm{kg})$ and xylazine $(4 \mathrm{mg} / \mathrm{kg})$ anaesthesia and subsequently injected daily subcutaneously (s.c.) with testosterone propionate $(5 \mathrm{mg} / \mathrm{kg}$, dissolved in sesame oil). This dose of testosterone propionate duplicates plasma levels of testosterone characteristic of gonadally intact males at the height of the breeding season and activates maximal levels of intromissive behaviour (19). All experiments were conducted in accordance with the guidelines set forth by NIH Guiding Principles for the Care and Use of Research Animals and were approved by Boston University (protocol \#99-017).

\section{Experiment 1: mating-induced Fos expression in galanin-IR neurones}

Heterosexual pairs of ferrets (six of each sex) were placed in a modified rabbit cage $(67 \times 67 \times 51 \mathrm{~cm})$. Mating in the ferret typically begins with the male neck-gripping the female. While maintaining the neck-grip, the male mounts the female and displays episodes of rapid pelvic thrusting. Usually, when the rapid pelvic thrusting ceases, the male has achieved penile intromission that often lasts longer than $1 \mathrm{~h}$. In the present study, the occurrence of intromission was always confirmed by feeling the genital region of the two ferrets. Ferrets were separated and returned to their home cages after the male intromitted with the female for 20-30 min Wersinger and Baum (18) found that a 5-min intromission was sufficient to induce high levels of Fos-IR in several forebrain sites of the female ferret's forebrain. Furthermore, Fos-IR was maximal $90 \mathrm{~min}$ after onset of intromission (18). Therefore, in the present study, the male as well as the female subjects were perfused 90 min after onset of intromission. Additional castrated, testosterone propionate-treated male $(n=3)$ and gonadally intact, oestrous female $(n=3)$ control ferrets were taken directly from their homecages and perfused.

\section{Experiment 2: mating-induced Fos expression in galanin-IR neurones in anosmic ferrets}

Nares of castrated, testosterone propionate-treated male ferrets were occluded using a method that was slightly modified from Buchman et al. (20). Following general anaesthesia with ketamine and xylazine, a topical anaesthetic (Cetacaine ${ }^{\circledR}$, Cetylite Industries Inc, Pennsauken, NJ, USA) was sprayed into both nares $(1 \mathrm{~s}$ spray $=200 \mathrm{mg})$ to suppress the sneezing reflex. VP mix ${ }^{\circledR}$ dental impression material (Henry Schein, Melville, NY, USA) was injected into each nasal cavity using silastic tubing. The injection tubing was inserted into each naris to a depth of $10 \mathrm{~mm}$, and the impression material was continuously injected while the tubing was slowly withdrawn, thereby ensuring complete occlusion of the naris (nares-occluded males, $n=5$ ). Sham-occluded animals $(n=5)$ were treated in the same manner as the nares-occluded males, except that the impression material was not injected. Subjects were observed closely both during and after recovery from the general anaesthesia for signs of respiratory difficulties. Nares-occluded ferrets breathed readily via their mouths. Anosmia in nares-occluded males was confirmed using an olfactory discrimination task (21). Briefly, prior to nares-occlusion, all subjects were trained to approach a peppermint odour in order to obtain a food reward in a Y-maze; for a description of the Y-maze, see (21). Subjects were food-deprived for $24 \mathrm{~h}$ before each trial. After nares-occlusion, the percentage of correct choices made by the nares-occluded males dropped to below $50 \%$ whereas sham-occluded males continued to identify the location of the food reward using the peppermint odour. After 2 weeks of recovery, nares- and shamoccluded males were first tested for odour preferences in the Y-maze (21). Following the last preference test, nares- and sham-occluded males were placed with a stimulus female in a modified rabbit cage (for dimensions, see Experiment 1) and allowed to intromit. As in Experiment 1, the occurrence of intromission was always confirmed by feeling the genital region of the two ferrets. In contrast with Experiment 1, all males were allowed to intromit for longer periods (up to $90 \mathrm{~min}$ whereupon all males were perfused with $4 \%$ paraformaldehyde). Thus, intromission durations ranged (mean \pm SEM) from 56 to $81(71 \pm 5)$ and from 16 to $75(44 \pm 15)$ min for sham-occluded and nares-occluded males, respectively.

Experiment 3: Fos expression in galanin-IR neurones after exposure to olfactory cues

Castrated, testosterone propionate-treated male ferrets $(n=8)$ were placed in the start box of the Y-maze. Air was blown over an anaesthetized (to exclude auditory cues) gonadally intact, oestrous female that was placed in one of the 
goal boxes. The door of the goal box was opaque and thus prevented subjects from seeing the stimulus female. Males remained in the start box for $60 \mathrm{~min}$ and thus were exposed to the odour stimulus for $60 \mathrm{~min}$. Then males were placed back in their home cage until they were perfused 30 min later (a total of 90 min after initial exposure to the odour stimulus). Additional castrated, testosterone propionate-treated males $(n=6)$ were placed for $60 \mathrm{~min}$ in the start box of the Y-maze without presentation of an odour stimulus (clean cage controls). They were then returned to their home cage until they were perfused $30 \mathrm{~min}$ later. A third group of castrated, testosterone propionatetreated males $(n=4)$ was placed on bedding soiled by an oestrous female in a modified rabbit cage (the same cage as used for mating) and perfused 90 min later.

\section{Perfusion}

Animals were injected intraperitoneally with pentobarbital $(100 \mathrm{mg} / \mathrm{kg}$; JA Webster, Leominster, MA, USA). The heart was exposed and $1000 \mathrm{U}$ of heparin ( $10000 \mathrm{U} / \mathrm{ml}$; Elkins-Sinn, Cherry Hill, NJ, USA) were injected into the left ventricle. Animals were perfused via the ascending aorta with approximately $50 \mathrm{ml}$ of $0.1 \mathrm{~m} \mathrm{PBS} \mathrm{(} \mathrm{pH}=7.4$ ), followed by $800 \mathrm{ml}$ (for females) or $1000 \mathrm{ml}$ (for males) of $4 \%$ paraformaldehyde in $0.1 \mathrm{M} \mathrm{PB}$ buffer $(\mathrm{pH}=7.2)$. After perfusion, the brains were immediately removed and post fixed in $4 \%$ paraformaldehyde for $2 \mathrm{~h}$. Brains were then transferred into a $30 \%$ sucrose/PBS solution for cryoprotection at $4{ }^{\circ} \mathrm{C}$ until they sank. Then brains were frozen with dry ice and sectioned coronally at $30 \mu \mathrm{m}$ using a ReichertJung SM2000R table top sliding microtome (Nossloch, Germany). Each brain section was saved in antifreeze solution $(500 \mathrm{ml} 0.1 \mathrm{~m}$ Tris-buffered saline, $300 \mathrm{ml}$ ethylene glycol, $300 \mathrm{~g}$ sucrose, $10 \mathrm{~g}$ polyvinylpyrrolidone and distilled water to a volume of 11 ) and maintained at $-20{ }^{\circ} \mathrm{C}$ for later dual label Fos-galanin-immunocytochemistry.

\section{Dual label Fos-galanin-immunocytochemistry}

Every fourth brain section was run for dual label Fos-galaninimmunocytochemistry. Free-floating sections were incubated in 3\% normal goat serum $/ 1 \% \mathrm{H}_{2} \mathrm{O}_{2} / \mathrm{PBS}$ for $90 \mathrm{~min}$ at room temperature and then in rabbit-anti-Fos primary antiserum (Experiment 1: DCH-1; 1:5,000, gift from Dr Gerard Evans; Experiments 2 and 3: SC52, 1:5000, Santa Cruz Biotechnology, Santa Cruz, CA, USA) for $16 \mathrm{~h}$ at room temperature. Sections were rinsed $3 \times 15 \mathrm{~min}$ with $0.1 \mathrm{M}$ PBS between each incubation. All incubations were carried out at room temperature. Sections were incubated with biotinylated goat antirabbit antibody (1:200; Vector Laboratories, Burlingame, CA, USA) for $2 \mathrm{~h}$ followed by avidin-biotin-complex (ABC; $1: 100$; Vector Laboratories) for $1.5 \mathrm{~h}$, and reacted with nickel diaminobenzidine (DAB; Vector laboratories; prepared according to the manufacturer's recommendation) for $7 \mathrm{~min}$. Then sections were incubated with rabbitantiporcine galanin primary antiserum $(1: 4000$; Chemicon International Inc, Temecula, CA, USA) for $16 \mathrm{~h}$, incubated with biotinylated goat antirabbit $(1: 200)$ for $2 \mathrm{~h}$ followed by ABC $(1: 100)$ for $1.5 \mathrm{~h}$. The sections were then reacted with 3-amino-9-ethylcarbazole (AEC; Vector Laboratories; prepared according to the manufacturer's recommendation) for $40 \mathrm{~min}$, mounted onto gelatin-coated slides, rinsed with distilled water, coated $3 \times$ with crystal mount (Biomeda Corp., Foster City, CA, USA) prior to being coverslipped with Permount (Fisher Scientific Co., Pittsburgh, PA, USA).

The specificity of the Fos (DCH-1) and galanin antibodies has been demonstrated previously in the ferret $(6,18)$. In Experiments 2 and 3 of the present study, we used a different Fos primary antiserum (SC52), which is commercially available (Santa Cruz Biotechnology) because we had run out of the noncommercial DCH-1. As a result, mating-induced Fos-IR levels were higher in males of Experiments 2 and 3 compared to those of Experiment 1. However, we believe the signal was specific since preincubation of the antiserum with Fos protein completely eliminated staining with SC52.

\section{Data analysis}

All slides were coded to conceal the sex and treatment of each subject. The numbers of Fos-IR galanin neurones were analysed in the dmPOA/AH, BNST and MA. A cell was considered galanin-IR if red reaction product was present within its cytoplasm. A galanin neurone was considered doublelabelled only if a black round Fos-IR nucleus was observed within the red galanin-IR cytoplasm (Fig. 1). The number of Fos-IR galanin neurones in the dmPOA/AH was analysed by dividing this area into four quadrants. For each quadrant, all Fos-IR, galanin-IR and Fos-IR galanin neurones
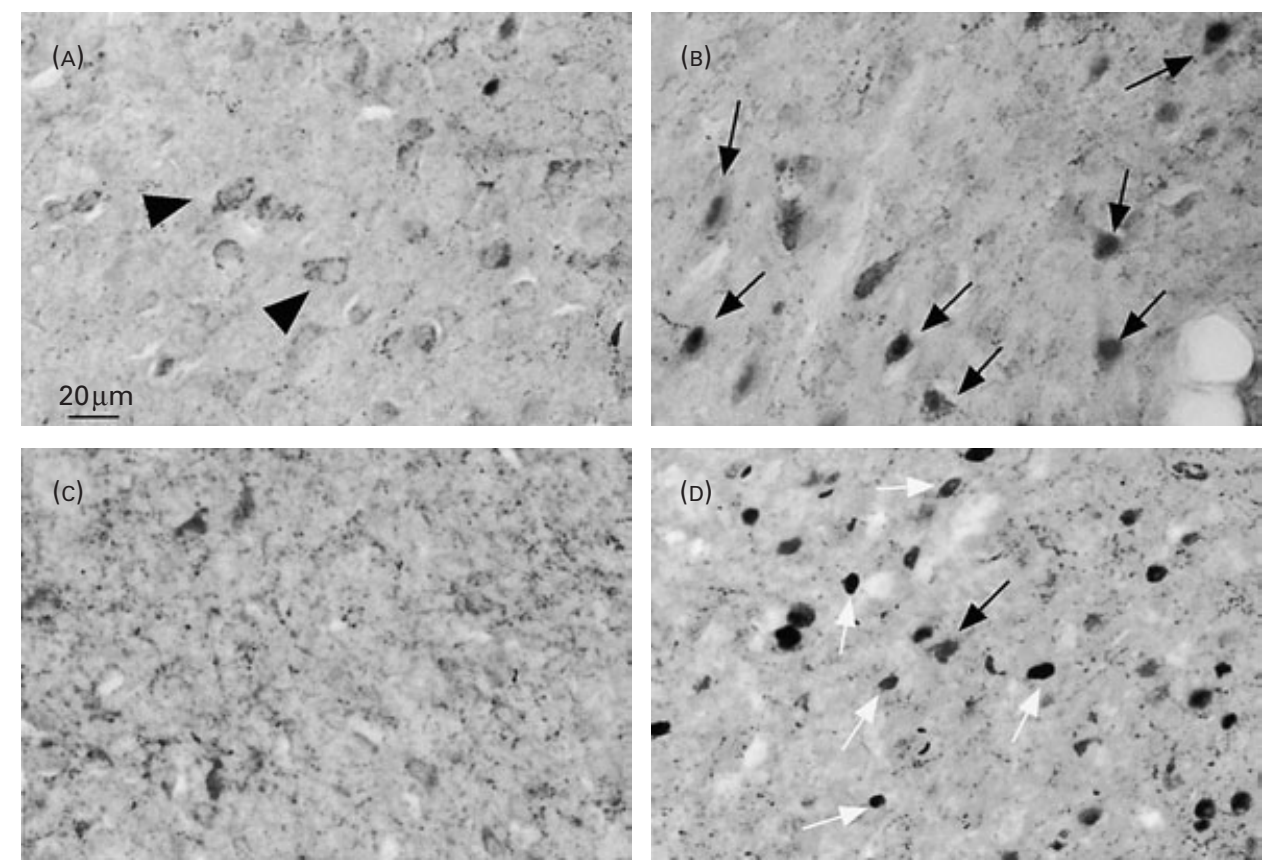

FIG. 1. Representative photomicrographs of mating-induced nuclear Fos-immunoreactive (IR) in galanin-IR neurones in the dorsomedial preoptic area/anterior hypothalamus of an unmated (A) and mated male (B) and an unmated (C) and mated female (D), respectively. Fos-IR was visualized using nickel diaminobenzidine as chromogen; galanin-IR was visualized in the same sections using 3-amino-9-ethylcarbazole as the chromogen. A galanin neurone was considered to be double-labelled only if a black round Fos-IR nucleus was observed within the red galanin-IR cytoplasm. Black arrows point to double-labelled Fos/galanin neurones in the mated male (в) and one in the mated female (D). White arrows point to some examples of single-labelled Fos neurones in the mated female (D). Arrowheads point to some examples of single-labelled galanin-IR neurones in the unmated male (A). 
visible in one field of view under a $\times 20$ objective (area $0.38 \mathrm{~mm}^{2}$ ) were traced onto a blank sheet of paper with the aid of a camera lucida microscope attachment. In addition, each double-labelled galanin neurone was examined under a $\times 40$ objective. Then all Fos-IR, galanin-IR and Fos-IR galanin cells present in the brain drawings were counted and numbers were combined for the four quadrants. In Experiment 1, two brain sections (which were $120 \mu \mathrm{m}$ apart so as to avoid double counting of labelled neurones) from the left hemisphere were analysed. We found no differences in total numbers of Fos-IR, galanin-IR and Fos-IR galanin cells between these two sections. Therefore, in Experiments 2 and 3, only one section from the left hemisphere of each subject was analysed. In all Experiments, the numbers of Fos-IR galanin neurones in the BNST and MA were analysed in a single brain section from the left hemisphere. All Fos-IR, galanin-IR and Fos-IR galanin cells visible in one field of view under a $\times 10$ objective (area of analysis: $1 \mathrm{~mm}^{2}$ and $0.60 \mathrm{~mm}^{2}$ for the BNST and MA, respectively) were traced onto a blank sheet of paper with the aid of a camera lucida attachment. In addition, each double-labelled galanin neurone was examined under a $\times 40$ objective. The percentage of Fos-IR galanin neurones was calculated by dividing the total number of Fos-IR galanin neurones by the total number of galanin-IR neurones (including single- and double-labelled neurones).

The numbers of Fos-IR in nongalanin neurones were counted in the medial POA, BNST, MA, cortical amygdala (ACo) and VLH (Fig. 2). These brain areas were selected because in previous studies $(18,22,23)$ mating or exposure to olfactory cues reliably induced Fos-IR in these sites. In Experiment 3, the numbers of Fos-IR in nongalanin neurones were counted in the areas described above as well as in the main olfactory bulb (MOB) and pirifirm cortex (Pir; Fig. 2). All Fos-IR nuclei visible in one field of view under a $\times 40$ (standard area: $0.1 \mathrm{~mm}^{2}$; MOB, medial POA, BNST, MA, VLH) or $\times 20$ (standard area: $0.38 \mathrm{~mm}^{2}$; ACo, Pir) objective were counted with the aid of a camera lucida microscope attachment.

No Fos and/or galanin staining was detected in one mated female in Experiment 1 and in one mated nares-occluded male in Experiment 2, probably because their brains were not adequately fixed during perfusion. Therefore, these animals were excluded from the study.

\section{Statistical analysis}

Group means were compared using a two-way (Experiment 1 ; sex $\times$ treatment) or a one-way (Experiments 2 and 3; treatment only) ANOvA; post-hoc comparisons of group means were made using Student-Newman-Keuls tests. A linear regression analysis was used for correlating intromission duration with percentage of Fos-IR galanin neurones in the dmPOA/AH, BNST and MA (Experiment 2 only). To analyse the number of Fos-IR nuclei in Experiment 3, we had strong a priori expectations that odours from oestrous females would induce Fos-IR in the main olfactory pathway $(22,23)$. Therefore, neuronal Fos values of males exposed to volatile odours or to soiled bedding from an oestrous female were compared with clean Y-maze control values using one-tailed $t$-tests.

\section{Results}

\section{Experiment 1: mating-induced Fos-IR in galanin neurones}

Achieving an intromission significantly induced Fos-IR in the nuclei of galanin-IR neurones in the dmPOA/AH of male ferrets, whereas no such induction of Fos-IR in galanin neurones occurred in females after receipt of an intromission (Figs 1 and 3). There was a significant sex-mating interaction in the dmPOA/AH $[\mathrm{F}(1,16)=6.1, \mathrm{P}=0.03]$. Post-hoc analysis revealed that the percentage of Fos-IR galanin neurones was significantly higher in mated males compared to mated females and unmated ferrets of both sexes (Fig. 3).

Mating with intromission induced Fos-IR in the nuclei of galanin neurones in the MA $[\mathrm{F}(1,16)=22, \mathrm{P}<0.001]$ of both sexes equally (Fig. 3). Post-hoc analysis showed that both mated males and females had a higher percentage of Fos-IR galanin neurones than unmated males and females, respectively. Furthermore, there was no difference in the percentage of Fos-IR galanin neurones between mated males and mated females. Mating with intromission induced Fos-IR in the nuclei of galanin neurones in the BNST $[\mathrm{F}(1,16)=8$, $\mathrm{P}=0.014$ ] (Fig. 3). Post-hoc analysis indicated that mated males had a higher percentage of Fos-IR galanin neurones than unmated males, while there was no difference between unmated and mated females. The absence of a significant difference between unmated and mated females was due to the high mean percentage of double-labelled neurones found in unmated females. Although two unmated females had no Fos-IR galanin neurones, one unmated female in this group had numerous Fos-IR galanin neurones, which inflated the group mean. It is noteworthy that mated males and mated
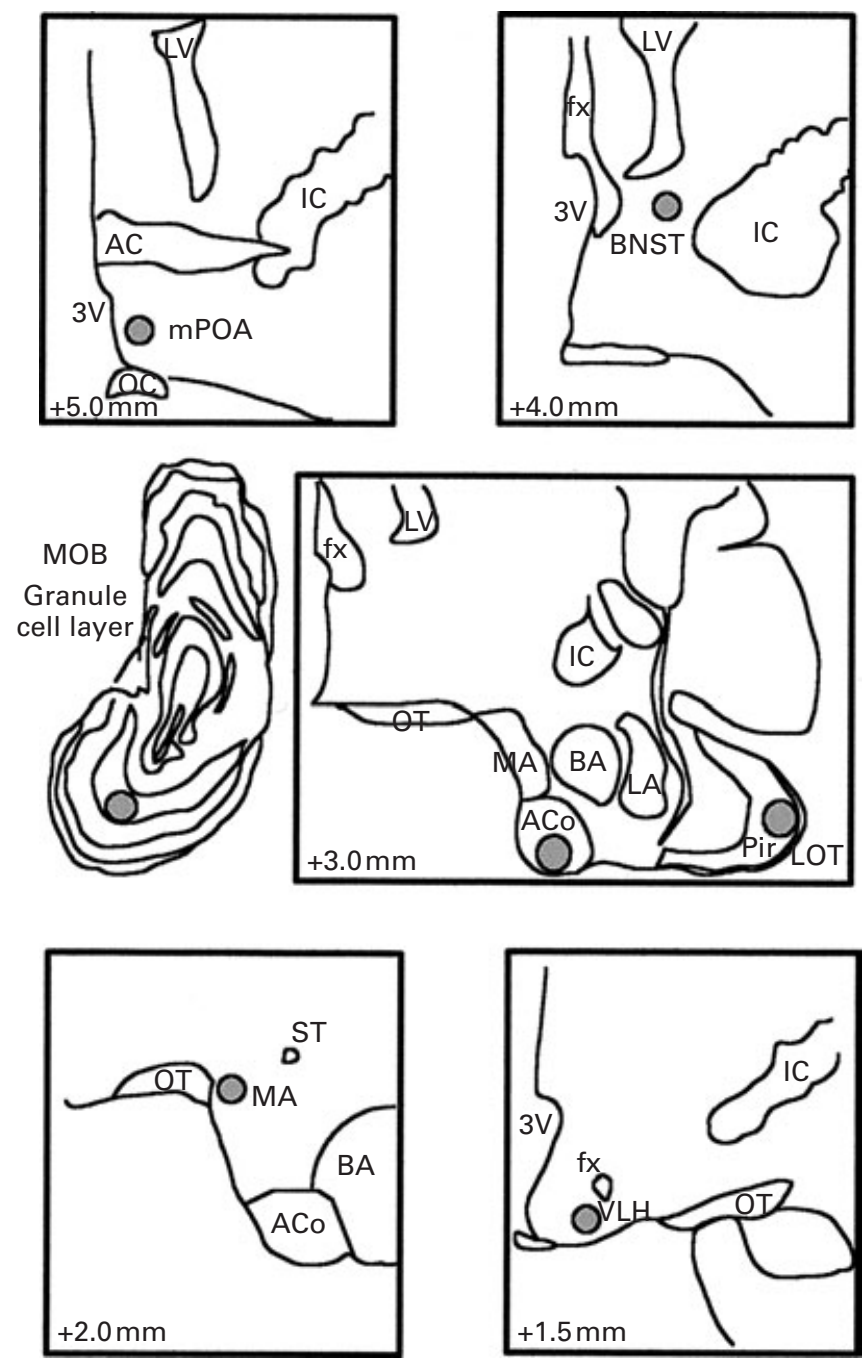

FIG. 2. Schematic drawings showing the location of the Fos-immunoreactive (IR) counting areas in the granule cell layer of the main olfactory bulb (MOB; $\left.0.1 \mathrm{~mm}^{2}\right)$, medial preoptic area (mPOA; $0.1 \mathrm{~mm}^{2}$ ), bed nucleus of the stria terminalis (BNST; $0.1 \mathrm{~mm}^{2}$ ), medial amygdala $\left(\mathrm{MA} ; 0.1 \mathrm{~mm}^{2}\right)$, anterior cortical amygdala $\left(\mathrm{ACo} ; 0.38 \mathrm{~mm}^{2}\right)$, pirifirm cortex (Pir; $0.38 \mathrm{~mm}^{2}$ ) and ventrolateral hypothalamus (V LH; $0.1 \mathrm{~mm}^{2}$ ). $3 \mathrm{~V}$, third ventricle; $\mathrm{AC}$, anterior commissure; BA, basolateral amygdala; fx, fornix; IC, internal capsule; LA, lateral amygdala; LOT, lateral olfactory tract; LV, lateral ventricle; OC, optic chiasm; OT, optic tract; st, stria terminalis. 

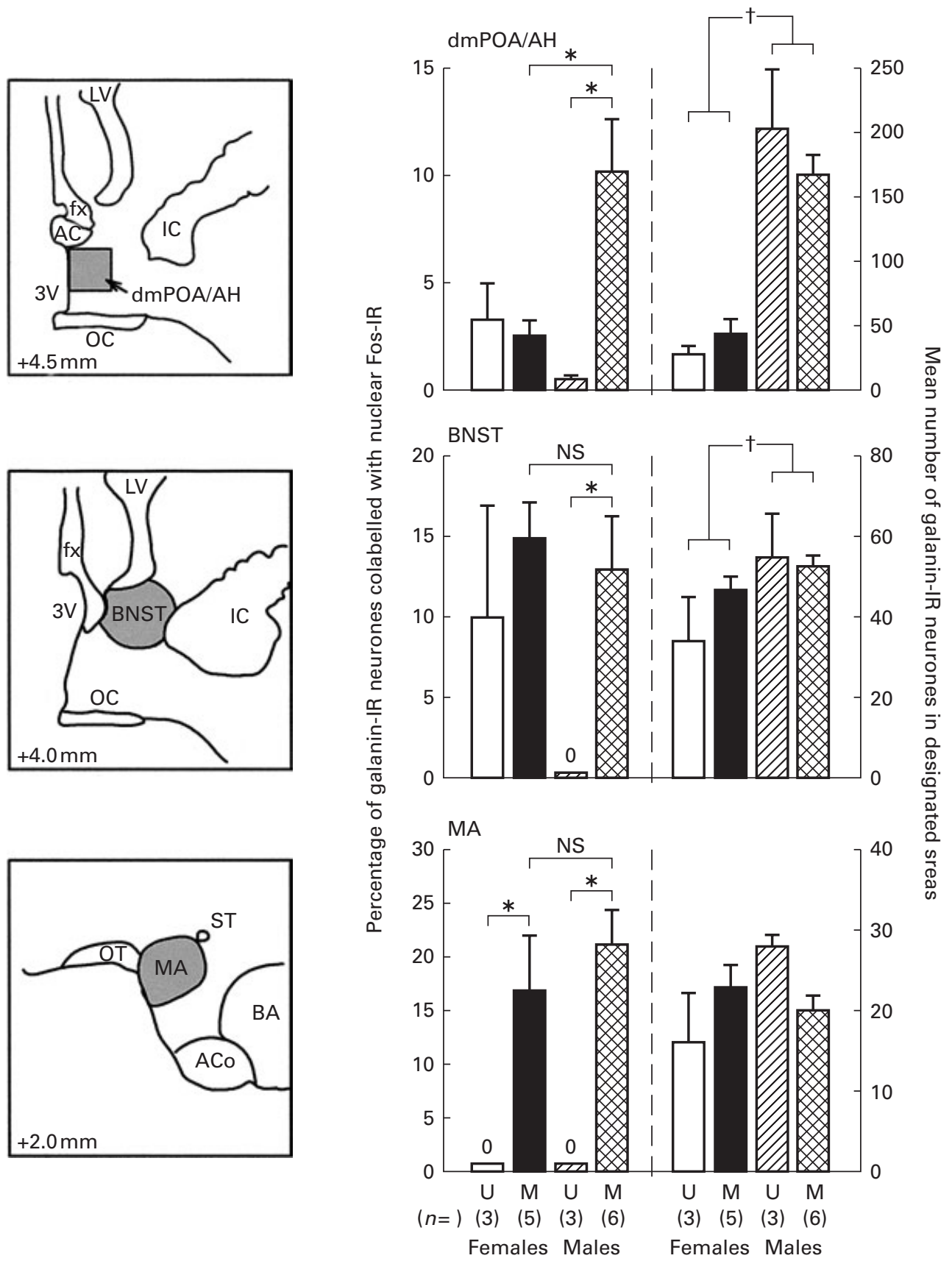

FIG. 3. Right: Effect of mating with intromission, either received by females or achieved by males, on the percentage of galanin-immunoreactive (IR) neurones that were colabelled with nuclear Fos-IR. Groups of galanin-IR neurones were analysed in the dorsomedial preoptic area/anterior hypothalamus (dmPOA/AH), bed nucleus of the stria terminalis (BNST) and medial amygdala (MA). The number of galanin-IR neurones in these regions is also shown. Data are expressed as mean $\pm \mathrm{SEM}$. ${ }^{*} \mathrm{P}<0.05$, post-hoc comparisons; NS, $\mathrm{P}>0.05$ post-hoc comparisons; $\uparrow$ significant effect of sex, $\mathrm{P}<0.05$. $\mathrm{U}=$ unmated; $\mathrm{M}=$ mated. Left: Schematic drawings showing the location of the different groups of galanin-IR neurones. The shaded areas represent the counting areas in the dmPOA/AH $\left(1.5 \mathrm{~mm}^{2}\right)$, BNST $\left(1 \mathrm{~mm}^{2}\right)$ and MA $\left(0.60 \mathrm{~mm}^{2}\right) .3 \mathrm{~V}$, third ventricle; AC, anterior commissure; BA, basolateral amygdala; fx, fornix; IC, internal capsule; LV, lateral ventricle; OC, optic chiasm; OT, optic tract; st, stria terminalis.

females had similar high mean percentages of Fos-IR galanin neurones in the BNST whereas in the dmPOA/AH the mean percentage of Fos-IR galanin neurones was significantly lower in females than in males (Fig. 3).

As previously (6) reported, there was a striking sex difference in the number of galanin-IR neurones in the ferret
$\mathrm{dmPOA} / \mathrm{AH}$, with males having three times as many galanin neurones as females (Fig. 3). In the present study, we also observed a small, but statistically significant sex difference in the number of galanin-IR neurones in the BNST, with males having more galanin neurones than females. Park et al. (6) also observed a nonsignificant trend towards more galanin-IR 
neurones in the BNST of breeding males versus oestrous females. In the present study, there was a significant effect of sex on number of galanin neurones in the dorsomedial $\mathrm{POA} / \mathrm{AH}[\mathrm{F}(1,16)=37, \mathrm{P}<0.001]$ and $\mathrm{BNST}[\mathrm{F}(1,16)=5$, $\mathrm{P}=0.05]$.

\section{Fos-IR in nongalanin neurones}

A sexually dimorphic pattern of neuronal Fos-IR was observed throughout the forebrain following mating: neuronal Fos-IR was augmented in the medial preoptic area (mPOA), dmPOA/AH, BNST and VLH in mated oestrous females only (Table 1). Neuronal Fos-IR was augmented only in the MA of mated castrated, testosterone propionatetreated males. There was a significant effect of sex and mating on the mean number of Fos-IR nuclei in the mPOA [sex: $\quad \mathrm{F}(1,16)=7.7, \quad \mathrm{P}=0.02 ; \quad$ mating: $\quad \mathrm{F}(1,16)=11.9$, $\mathrm{P}=0.004]$, BNST [sex: $\mathrm{F}(1,16)=5.2, \mathrm{P}=0.04$; mating: $\mathrm{F}(1,16)=6.4, \mathrm{P}=0.03]$, MA $[\operatorname{sex}: \mathrm{F}(1,16)=17, \mathrm{P}=0.001$; mating: $\quad \mathrm{F}(1,16)=31.5, \quad \mathrm{P}<0.001]$ and VLH [sex: $\mathrm{F}(1,16)=94, \mathrm{P}<0.001$; mating: $\mathrm{F}(1,16)=120, \mathrm{P}<0.0001]$. In addition, there was a significant sex-mating interaction in the mPOA $[\mathrm{F}(1,16)=6.6, \mathrm{P}=0.02], \mathrm{MA}[\mathrm{F}(1,16)=8.5$, $\mathrm{P}<0.001]$ and VLH $[\mathrm{F}(1,16)=94, \mathrm{P}<0.001]$. Post-hoc analysis revealed that mating induced neuronal Fos-IR in the mPOA, BNST and VLH of females only. Mated castrated, testosterone-propionate treated males showed equivalently low levels of neuronal Fos-IR as unmated ferrets of both sexes, with the exception of the MA; there was a significant, albeit lower than in females, induction of neuronal Fos-IR in this brain site (Table 1). These results confirm previous findings from our laboratory (23). Counts of Fos-IR neurones in the dmPOA/AH taken when analysing the number of double-labelled Fos-IR galanin neurones in this area (see Fig. 3 for the counting region) also pointed to a significant effect of mating [mating: $\mathrm{F}(1,16)=6.1, \mathrm{P}=0.03$ ] (Table 1). There was no effect of $\operatorname{sex}[\mathrm{F}(1,16)=2.5, \mathrm{P}=0.14]$ or a sex-mating interaction $[\mathrm{F}(1,16)=2.4, \mathrm{P}=0.15]$ indicating that mating induced Fos-IR equivalently in both sexes, although the number of Fos-IR neurones seems to be much higher in mated females compared to mated males (Table 1).

Table 1. Mean ( \pm SE) Number of Fos-Immunoreactive Nuclei in Nongalanin Neurones of Different Forebrain Regions of Unmated and Mated Male and Female Ferrets.

\begin{tabular}{lcccccc}
\hline Group & $\mathrm{n}$ & $\mathrm{MA}$ & $\mathrm{BNST}$ & $\mathrm{mPOA}$ & $\mathrm{dmPOA} / \mathrm{AH}$ & $\mathrm{VLH}$ \\
\hline $\begin{array}{c}\text { Unmated } \\
\text { females }\end{array}$ & 3 & $10 \pm 7$ & $2.3 \pm 1.5$ & $1.3 \pm 0.7$ & $2 \pm 2$ & $0.7 \pm 0.5$ \\
$\begin{array}{c}\text { Mated } \\
\text { females }\end{array}$ & 5 & $50 \pm 4^{*}$ & $38 \pm 11^{*}$ & $38 \pm 8^{*}$ & $128 \pm 44^{*}$ & $78 \pm 5^{*}$ \\
$\begin{array}{c}\text { Unmated } \\
\text { males }\end{array}$ & 3 & $5 \pm 3$ & $0.3 \pm 0.3$ & $0.1 \pm 0.1$ & $1.3 \pm 0.7$ & $1 \pm 0.7$ \\
$\begin{array}{c}\text { Mated } \\
\text { males }\end{array}$ & 6 & $17 \pm 2^{*} \dagger$ & $4.3 \pm 1.8$ & $5.3 \pm 1.6$ & $30 \pm 8^{*}$ & $5.3 \pm 1.2$ \\
\hline
\end{tabular}

Data are expressed as mean \pm SEM. *Significantly $(\mathrm{P}<0.05)$ different from unmated subjects. †Significantly $(\mathrm{P}<0.05)$ different from mated females. MA, medial amygdala; BNST, bed nucleus of the stria terminalis; $\mathrm{mPOA}$, medial preoptic area; $\mathrm{dmPOA} / \mathrm{AH}$, dorsomedial preoptic area/anterior hypothalamus; VLH, ventrolateral hypothalamus.
Experiment 2: mating-induced Fos expression in galanin-IR neurones in anosmic ferrets

\section{Fos-IR in galanin neurones}

Achieving intromission induced equivalent levels of Fos-IR in galanin-IR neurones in the dmPOA/AH, BNST and MA of both nares- and sham-occluded males (Table 2). There was a significant positive correlation between intromission duration and the percentage of Fos-IR galanin neurones in the dmPOA/AH $(\mathrm{R}=0.85, \mathrm{P}=0.004)$, but not the BNST or MA: the longer the intromission, the higher the percentage of Fos-IR galanin neurones in the dmPOA/AH (Fig. 4). Surprisingly, there was a significant effect of treatment on the number of galanin-IR neurones in the $\mathrm{dmPOA} / \mathrm{AH}$ $[\mathrm{F}(1,8)=85.2, \mathrm{P}<0.001]$ with nares-occluded males having significantly more galanin-IR neurones in this brain site than sham-occluded males (Table 2). We have no explanation for this finding.

\section{Fos-IR in nongalanin neurones}

Bilateral nares-occlusion decreased mating-induced neuronal Fos-IR in several forebrain regions that receive olfactory inputs, including the ACo, MA and BNST of castrated, testosterone propionate-treated male ferrets (Table 3). There was a significant effect of treatment on number of Fos-IR nuclei in the ACo $[\mathrm{F}(1,8)=22.9, \mathrm{P}=0.002]$, the MA $[F(1,8)=5.5, P=0.05]$ and the BNST $[F(1,8)=8.9$, $\mathrm{P}=0.02]$.

\section{Experiment 3: Fos expression in galanin-IR neurones after exposure to olfactory cues}

Exposure to volatile or nonvolatile odours from an oestrous female failed to induce Fos-IR in galanin neurones in the dmPOA/AH, BNST or MA (Table 4). By contrast, exposure to bedding soiled by an oestrous female, but not volatile odours from an oestrous female, significantly induced Fos-IR

TABLE 2. Induction of Fos-Immunoreactive (IR) in the Nuclei of Galanin Neurones in the dmPOA/AH, BNST and MA of Castrated, TP-Treated Male Ferrets in which Both Nares Were Either Occluded (nares-occluded) or Left Open (sham-occluded). All Male Subjects Were Paired with an Ovo-Hysterectomized Female Brought into Behavioural Oestrus by Injections with Oestradiol Benzoate, and Allowed to Intromit.

\begin{tabular}{lcccc}
\hline Group & $\mathrm{n}$ & $\mathrm{dmPOA} / \mathrm{AH}$ & $\mathrm{BNST}$ & $\mathrm{MA}$ \\
\hline \% galanin-IR neurones & colabelled with Fos-IR \\
Sham-occluded & 5 & $67 \pm 2$ & & \\
Nares-occluded & 4 & $47 \pm 13$ & $24 \pm 4$ & $56 \pm 8$ \\
No. galanin-IR neurones in designated areas & & \\
Sham-occluded & 5 & $164 \pm 4$ & $40 \pm 6$ \\
Nares-occluded & 4 & $219 \pm 4 *$ & $52 \pm 4$ & $12 \pm 2$ \\
\hline
\end{tabular}

Data are expressed as mean \pm SEM. ${ }^{*}$ Significantly $(\mathrm{P}<0.05)$ different from sham-occluded males. MA, medial amygdala; BNST, bed nucleus of the stria terminalis; $\mathrm{dmPOA} / \mathrm{AH}$, dorsomedial preoptic area/anterior hypothalamus. 


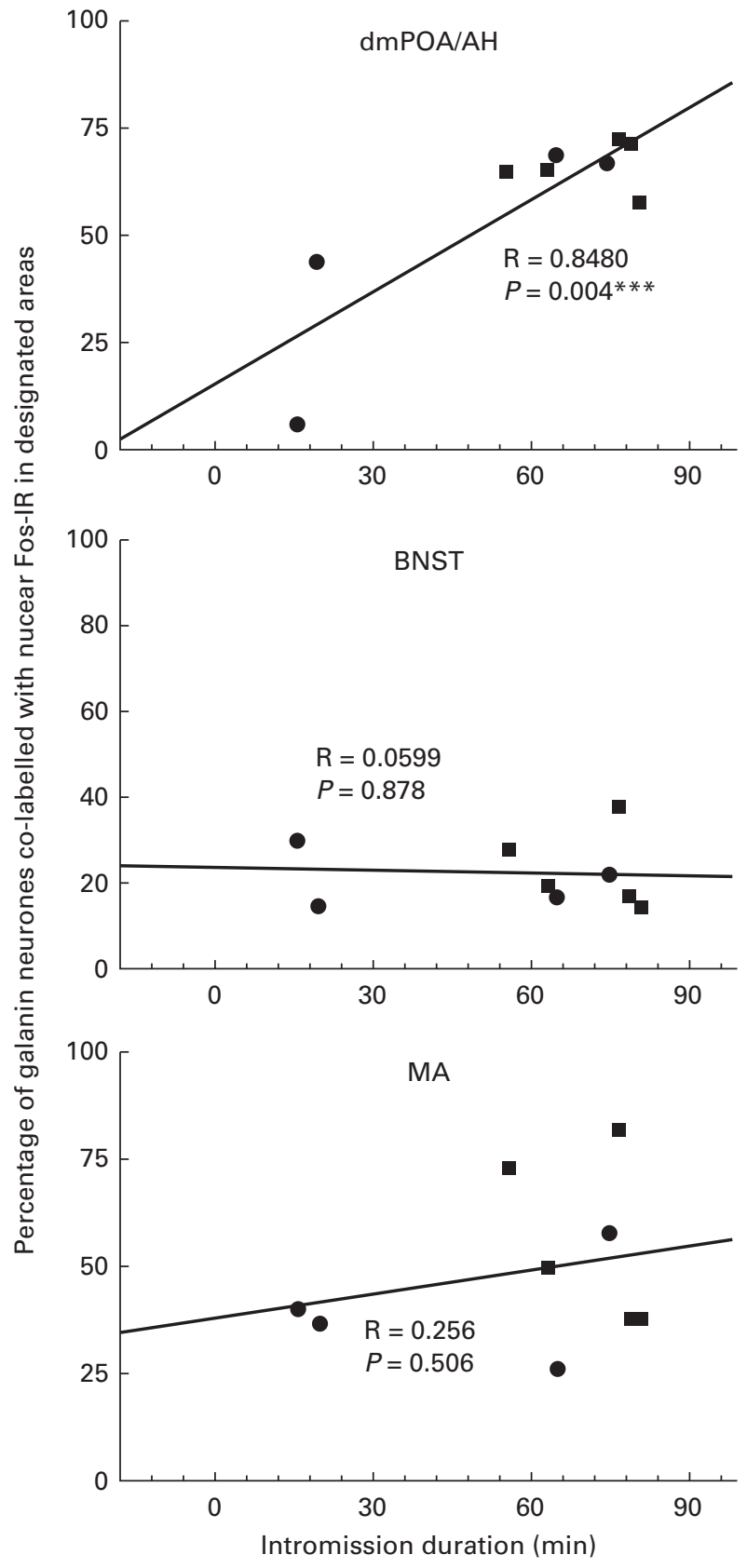

FIG. 4. Correlation between the percentage of galanin-immunoreactive (IR) neurones colabelled with nuclear Fos-IR and intromission duration in three different brain regions of male ferrets whose nares were either bilaterally-occluded ( $)$ or sham-occluded ( $\boldsymbol{\square})$. Groups of galaninIR neurones were analysed in the dorsomedial preoptic area/anterior hypothalamus (dmPOA/AH), bed nucleus of the stria terminalis (BNST) and medial amygdala (MA).

in the MOB (clean Y-maze: $34 \pm 6$; volatile oestrous odours in Y-maze: $58 \pm 15$; soiled oestrous bedding: $155 \pm 48$ ) and ACo (clean Y-maze: $5 \pm 1$; volatile oestrous odours in Y-maze: $9 \pm 2$; soiled oestrous bedding: $20 \pm 10$ ), but not in other forebrain areas, including the MA, mPOA and BNST. There was a significant effect of oestrous bedding on the number of Fos-IR nuclei in the MOB $[t[8]=-3.13$,
Table 3. Mean $( \pm \mathrm{SE})$ Number of Fos-Immunoreactive Nuclei in Nongalanin Neurones of Different Forebrain Regions of Castrated, TP-Treated Male Ferrets in which Both Nares Were Either Occluded (Nares-Occluded) or Left Open (Sham-Occluded). All Male Subjects Were Paired with an Ovo-Hysterectomized Female Brought into Behavioural Oestrus by Injections with Oestradiol Benzoate, and Allowed to Intromit.

\begin{tabular}{lccllll}
\hline Group & $\mathrm{n}$ & ACO & MA & BNST & MPOA & VLH \\
\hline Sham-occluded & 5 & $28 \pm 4$ & $23 \pm 2$ & $55 \pm 6$ & $30 \pm 5$ & $6 \pm 1$ \\
Nares-occluded & 4 & $5 \pm 1^{*}$ & $15 \pm 2^{*}$ & $23 \pm 7^{*}$ & $21 \pm 5$ & $6 \pm 1$ \\
\hline
\end{tabular}

$* \mathrm{P}<0.05$ compared to sham-occluded males. Aco, cortical amygdala; MA, medial amygdala; BNST, bed nucleus of the stria terminalis; mPOA, medial preoptic area; VLH, ventrolateral hypothalamus.

TABlE 4. Absence of a Significant Induction of FosImmunoreactive (IR) in the Nuclei of Galanin Neurones in the dmPOA/AH, BNST and MA of Castrated, TP-Treated Males by Volatile or Nonvolatile Odours from an Oestrous Female.

\begin{tabular}{|c|c|c|c|c|}
\hline Group & $\mathrm{n}$ & dmPOA/AH & BNST & MA \\
\hline \multicolumn{5}{|c|}{$\%$ galanin-IR neurones colabelled with Fos-IR } \\
\hline Clean Y-maze & 6 & $0.4 \pm 0.2$ & $0.3 \pm 0.3$ & $0 \pm 0$ \\
\hline $\begin{array}{l}\text { Volatile oestrous odours in } \\
\text { Y-maze }\end{array}$ & 8 & $0.2 \pm 0.2$ & $0 \pm 0$ & $0 \pm 0$ \\
\hline On soiled oestrous bedding & 4 & $0.3 \pm 0.3$ & $1 \pm 1$ & $0 \pm 0$ \\
\hline \multicolumn{5}{|c|}{ No. galanin-IR neurones in designated areas } \\
\hline Clean Y-maze & 6 & $178 \pm 32$ & $55 \pm 3.7$ & $23 \pm 3$ \\
\hline $\begin{array}{l}\text { Volatile oestrous odours in } \\
\text { Y-maze }\end{array}$ & 8 & $183 \pm 15$ & $54 \pm 4.1$ & $20 \pm 2$ \\
\hline On soiled oestrous bedding & 4 & $169 \pm 6$ & $64 \pm 6$ & $23 \pm 4$ \\
\hline
\end{tabular}

Data are expressed as mean \pm SEM. MA, medial amygdala; BNST, bed nucleus of the stria terminalis; dmPOA/AH, dorsomedial preoptic area/anterior hypothalamus.

$\mathrm{P}=0.007]$ and ACo $[t[8]=-2.01, \mathrm{P}=0.04]$. Thus, odours were clearly detected by the main olfactory system in males exposed to oestrous bedding. However, they failed to induce Fos-IR in the nuclei of galanin neurones in the $\mathrm{dmPOA} / \mathrm{AH}$, BNST or MA.

\section{Discussion}

The present study shows that galanin neurones in the dmPOA/AH were activated in response to genital somatosensory inputs in males whereas no such activation occurred in the smaller population of galanin neurones present in the female dmPOA/AH. By contrast, mating with intromission induced Fos-IR in the nondimorphic population of galanin-IR neurones in the MA equally in the two sexes. We also suggest that mating with intromission was equally effective in inducing Fos-IR in galanin-IR neurones of the BNST in the two sexes in that mated males and mated 
females had a similar high percentage of Fos-IR galanin neurones in this brain region. This raises the possibility that the sexually dimorphic galanin neurones in the dmPOA/AH perform some mating-dependent function that occurs only in males.

The activation of galanin neurones in the male ferret's hypothalamus does not seem to rely on olfactory cues associated with mating. Bilateral occlusion of the nares, a procedure that successfully blocked olfactory inputs to the forebrain (21, present study), had no effect on the percentage of mating-induced Fos-IR in the nuclei of galanin neurones in either the dmPOA/AH, BNST or MA. Furthermore, exposure to soiled bedding or volatile odours from an oestrous female failed to induce Fos-IR in the nuclei of galanin neurones in any brain region of castrated, testosterone propionate-treated male ferrets. Our results strongly suggest that galanin neurones in the $\mathrm{dmPOA} / \mathrm{AH}$, BNST and MA are activated by genital somatosensory as opposed to olfactory inputs. Our finding that longer intromissions resulted in greater numbers of galanin-IR neurones being activated in the dmPOA/AH gives further support to this hypothesis. In the present study, however, we did not investigate whether achieving neck-grips or neck-grips plus mounting the female (in the absence of penile intromission) would activate galanin neurones in the dmPOA/AH. Therefore, we cannot rule out the possibility that galanin neurones in the male hypothalamus are activated by sensory stimuli derived from neckgripping and mounting the female.

The sexually dimorphic activation of galanin neurones in the male ferret's dmPOA/AH by genital somatosensory inputs raises questions about their function in the male ferret. One obvious possibility is that these galanin neurones are part of a neural circuit that controls the display of male coital behaviour. There are, however, conflicting reports on the function of galanin in male coital behaviour in the rat $(12,14)$. Poggioli et al. (14) reported that i.c.v. administration of galanin decreased frequencies of mounts and intromissions whereas Benelli et al. (15) found that administration of galantide, a specific galanin receptor antagonist, facilitated these behaviours in male rats. By contrast, intra-POA/AH infusion of galanin facilitated masculine sexual behaviour in gonadectomized, testosterone-treated male and female rats $(12,13)$. However, Park and Baum (16) found no effect of i.c.v. administration of galanin or the galanin receptor antagonist M-40 on male coital behaviour in the male ferret. By contrast, heterosexual partner preference was reduced by i.c.v. administration of M-40 in both sexes suggesting that galanin facilitates appetitive aspects of sexual behaviour. It seems unlikely, however, that galanin neurones in the dmPOA/AH mediate appetitive aspects of sexual behaviour. First, this population of galanin neurones is highly sexually dimorphic and also appears to be activated in a sexually dimorphic manner by mating-associated stimuli. Both sexes responded with a reduction in heterosexual preference when injected i.c.v. with M-40 (16). Second, bilateral naresocclusion had no effect on the percentage of mating-induced Fos-IR galanin neurones in the dmPOA/AH (or BNST and MA) of male ferrets, whereas this procedure completely eliminated their preference for an oestrous female indicating that mate recognition and mate choice predominantly rely on olfactory cues in this species (21). Similarly, exposure to volatile or nonvolatile odour cues failed to augment Fos-IR in galanin neurones in the dmPOA/AH (or the BNST and MA). Thus, a role for dmPOA/AH galanin neurones in appetitive aspects of sexual behaviour can probably be ruled out.

The dmPOA/AH galanin neurones, together with groups of galanin neurones in the BNST and MA, are apparently part of a neural circuit that processes somatosensory information derived from penile intromission. One possibility is that galanin neurones in the $\mathrm{dmPOA} / \mathrm{AH}$ are involved in the regulation of sexual satiety. The male ferret typically makes long intromissions; a single intromission often lasts longer than $1 \mathrm{~h}$. Mating-induced galanin neuronal activation in the dmPOA/AH may inhibit sexual arousal, ultimately leading to a termination of the intromission. A possible role for galanin in sexual satiety has also been proposed for the male rat by Veening and Coolen (24). In the subparafascicular nucleus (SPFp), Fos-IR neurones (induced by achieving ejaculation with an oestrous female) were found in close apposition with galanin-IR fibres. The SPFp has extensive projections to the MA (25-27) and POA $(28,29)$. These galanin-IR fibres probably originate in the lumbosacral spinal cord; however, whether these galanin-IR fibres are terminating or just passing through the SPFp is unknown. It seems unlikely that galanin cell bodies in the dmPOA/AH are actually functionally associated with these galanin fibres in the SPFp. More research using antero- and retrograde tracers is needed to elucidate the afferents and efferents of the sexually dimorphic population of galanin neurones in the ferret dmPOA/AH.

The intromission-induced activation of $\mathrm{dmPOA} / \mathrm{AH}$ galanin neurones in the male ferret is particularly interesting in light of the sex difference in the ability to generate preovulatory luteinizing hormone $(\mathrm{LH})$ surges in this species (17). The ferret is a reflexively ovulating species, in which the preovulatory LH surge is induced by genitalsomatosensory stimuli associated with mating instead of by ovarian steroids alone as in spontaneously ovulating species (30). Thus, receipt of an intromission induces a prolonged $(+12 \mathrm{~h})$ preovulatory surge in the oestrous female ferret whereas achieving intromission inhibits $\mathrm{LH}$ release in the breeding male $(17,31)$. This sex dimorphism in matinginduced LH secretion most likely reflects sex differences in the neural inputs to mediobasal hypothalamic $(\mathrm{MBH}) \mathrm{GnRH}$ neurones. Indeed, mating with intromission induced Fos-IR in the nuclei of $\mathrm{MBH} \mathrm{GnRH}$ neurones in oestrous female, but not male ferrets $(23,32)$. Furthermore, the distribution of mating-induced Fos-IR in forebrain regions was found to be sexually dimorphic: neuronal levels of Fos-IR were significantly higher in the medial POA, BNST and VLH of oestrous females compared to breeding males (23, present study). The sexual dimorphism in the distribution of mating-induced Fos-IR in non-GnRH neurones could reflect a tonic inhibition of portions of the input pathway to $\mathrm{MBH} G \mathrm{GRH}$ neurones in the male ferret. As stated in the introduction, the dmPOA/AH/AH has been associated with inhibiting female-typical proceptive behaviours in the male ferret (3-5). It is possible that neurones in the $\mathrm{dmPOA} / \mathrm{AH}$ also inhibit female-typical neuroendocrine responses, such as the preovulatory LH surge, to sensory cues associated with 
mating. Thus, the activation of galanin neurones in the dmPOA/AH by genital-somatosensory stimuli in the male ferret raises the question whether galanin released from these neurones inhibits the activation of $\mathrm{MBH} \mathrm{GnRH}$ neurones thereby preventing the induction of a preovulatory LH surge? There is substantial evidence that galanin acts as an inhibitory modulator of cholinergic and noradrenergic transmission (33-37). In rats, galanin is coexpressed in a large proportion of noradrenergic cells in the locus coereleus (LC; A6), as well as in caudal parts of the nucleus of the solitary tract (A2) (38). Application of galanin directly onto LC neurones in an in vitro slice preparation caused hyperpolarization of these neurones $(37,39)$. Furthermore, a recent study by Todd et al. (36) suggested an inhibitory role of galanin in pituitary LH release in rats. Application of galanin suppressed GnRH-induced LH release from pituitary fragments of proestrous female rats. More research using intra-dmPOA/AH infusions of a galanin antagonist is needed to test the hypothesis that galanin might inhibit the preovulatory activation of $\mathrm{MBH}$ GnRH neurones and consequent pituitary $\mathrm{LH}$ release in the male ferret.

\section{Acknowledgements}

We thank the animal care staff at Boston University for taking care of our ferrets. This work was supported by NIH Grant HD21094 (MJB) and DC00426-02 (SKW).

\section{Accepted 8 October 2001}

\section{References}

1 Tobet SA, Zahniser DJ, Baum MJ. Differentiation in male ferrets of a sexually dimorphic nucleus of the preoptic/anterior hypothalamic area requires prenatal estrogen. Neuroendocrinology 1986; 44: 299-308.

2 Cherry JA, Basham ME, Weaver CE, Krohmer RW, Baum MJ. Ontogeny of the sexually dimorphic male nucleus in the preoptic/anterior hypothalamus of ferrets and its manipulation by gonadal steroids. J Neurobiol 1990; 21: 844-857.

3 Paredes RG, Baum MJ. Altered sexual partner preference in male ferrets given excitotoxic lesions of the preoptic area/anterior hypothalamus. J Neurosci 1995; 15: 6619-6630.

4 Kindon HA, Baum MJ, Paredes RJ. Medial preoptic/anterior hypothalamic lesions induce a female-typical profile of sexual partner preference in male ferrets. Horm Behav 1996; 30: 514-527.

5 Cherry JA, Baum MJ. Effects of lesions of a sexually dimorphic nucleus in the preoptic area/anterior hypothalamus area on the expression of androgen and estrogen-dependent behavior in male ferrets. Brain Res 1990; 522: 191-203.

6 Park J-J, Baum MJ, Tobet SA. Sex difference and steroidal stimulation of galanin immunoreactivity in the ferret's dorsal preoptic area/anterior hypothalamus. J Comp Neurol 1997; 389: 277-288.

7 Cornbrooks EB, Parsons RL. Sexually dimorphic distribution of a galanin-like peptide in the central nervous system of the teleost fist Poecilia latipinna. J Comp Neurol 1991; 304: 639-665.

8 Prasada Rao PD, Murthy CK, Cook H, Peter RE. Sexual dimorphism of galanin-like immunoreactivity in the brain and pituitary of goldfish, Carassius auratus. J Chem Neuroanat 1996; 10: 119-135.

9 Mathieson WB, Taylor SW, Marshall M, Neumann PE. Strain and sex differences in the morphology of the medial preoptic nucleus of mice. J Comp Neurol 2000; 428: 254-265.

10 Bloch GJ, Eckersell C, Mills R. Distribution of galanin-immunoreactive cells within sexually dimorphic components of the medial preoptic area of the male and female rat. Brain Res 1993; 620: 259-268.
11 Ulibarri C, Rust N. Sex differences in the number of galanin and CGRP immunoreactive cells in the sexually dimorphic area of the hypothalamus of Mongolian gerbils. Soc Neurosci Abstract 1996; 22: 2070.

12 Bloch GJ, Butler PC, Kohlert JG, Bloch DA. Microinjection of galanin into the medial preoptic nucleus facilitates copulatory behavior in the male rat. Physiol Behav 1993; 54: 615-624.

13 Bloch GJ, Butler PC, Kohlert JG. Galanin microinjected into the medial preoptic nucleus facilitates female- and male-typical sexual behaviors in the female rat. Physiol Behav 1996; 59: 1146-1154.

14 Poggioli R, Rasori E, Bertolini A. Galanin inhibits sexual behavior in male rats. Eur J Pharmacol 1992; 213: 87-90.

15 Benelli A, Arletti R, Bertolini A, Menozzi B, Basaglia R, Poggioli R. Galantide stimulates sexual behavior in male rats. Eur J Pharmacol 1994; 260: 279-282.

16 Park J-J, Baum MJ. Intracerebroventricular infusion of the galanin antagonist M40 attenuates heterosexual partner preference in ferrets. Behav Neurosci 1999; 113: 391-400.

17 Carroll S, Erskine MS, Baum MJ. Sex difference in the effect of mating on the pulsatile secretion of luteinizing hormone in a reflex ovulator, the ferret. Endocrinology 1987; 121: 1349-1359.

18 Lambert GM, Baum MJ. Reciprocal relationships between pulsatile androgen secretion and the expression of mating behavior in adult male ferrets. Horm Behav 1991; 25: 382-393.

19 Wersinger SR, Baum MJ. The temporal pattern of mating-induced immediate-early gene product immunoreactivity in LHRH and nonLHRH neurons of the estrous forebrain. J Neuroendocrinol 1996; 8: $345-359$.

20 Buchman CA, Doyle WJ, Swarts JB, Bluestone CD. Effects of nasal obstruction on eustachian tube function and middle ear pressure. Acta Otolaryngol 1999; 119: 351-355.

21 Kelliher KR, Baum MJ. Nares occlusion eliminates heterosexual partner selection without disrupting coitus in ferrets of both sexes. $J$ Neurosci 2001; 21: 5832-5840.

22 Kelliher KR, Chang YM, Wersinger SR, Baum MJ. Sex difference and testosterone modulation of pheromone-induced neuronal fos in the ferret's main olfactory bulb and hypothalamus. Biol Reprod 1998; 59: $1454-1463$.

23 Wersinger SR, Baum MJ. Sexually dimorphic processing of somatosensory and chemosensory inputs to forebrain luteinizing hormonereleasing hormone neurons in mated ferrets. Endocrinology 1997; 138: $1121-1129$.

24 Veening JG, Coolen LM. Neural activation following sexual behavior in the male and female rat brain. Behav Brain Res 1998; 92: 181-193.

25 LeDoux JE, Farb CR, Romanski LM. Overlapping projections to the amygdala and striatum from auditory processing areas of the thalamus and cortex. Neurosci Lett 1991; 134: 139-144.

26 LeDoux JE. Emotional memory systems in the brain. Behav Brain Res 1993; 58: 69-79.

27 Yasui Y, Saper CB, Cechetto DF. Calcitonin gene-related peptide (CGRP) immunoreactive projections from the thalamus to the striatum and amygdala in the rat. J Comp Neurol 1991; 308: 293-310.

28 Simerly RB, Swanson LH. The organization of neural inputs to the medial preoptic nucleus of the rat. J Comp Neurol 1986; 266: $312-342$.

29 Coolen LM, Peters HJPW, Veening JG. Anatomical interrelationships of the medial preoptic area and other brain regions activated following male sexual behavior. A combined Fos and tract-tracing study. J Comp Neurol 1998; 397: 421-435.

30 Bakker J, Baum MJ. Neuroendocrine regulation of GnRH release in induced ovulators. Front Neuroendocrinol 2000; 21: 220-262.

31 Carroll RS, Erskine MS, Doherty PC, Lundell LA, Baum MJ. Coital stimuli controlling luteinizing hormone secretion and ovulation in the female ferret. Biol Reprod 1985; 32: 925-933.

32 Lambert GM, Rubin BS, Baum MJ. Sex difference in the effect of mating on c-fos expression in luteinizing hormone-releasing hormone neurons of the ferret forebrain. Endocrinology 1992; 131: 1473-1480.

33 Consolo S, Palazzi E, Bertorelli R, Fisone G, Crawley JN, Hokfelt T, Bartfai T. Functional aspects of acetylcholine-galanin coexistence in the brain. Prog Brain Res 1990; 84: 279-287.

34 Olianas MC, Onali P, Neff NH, Costa E. Adenylate cyclase activity of synaptic membranes from rat striatum: inhibition by muscarinic receptor agonists. Mol Pharmacol 1983; 23: 393-398. 
35 Papas S, Bourque CW. Galanin inhibits continuous and phasic firing in rat hypothalamic magnocellular neurosecretory cells. J Neurosci 1997; 17: 6048-6056.

36 Todd JF, Small CJ, Akinsanya KO, Stanley SA, Smith DM, Bloom SR. Galanin is a paracrine inhibitor of gonadotroph function in the female rat. Endocrinology 1998; 139: 4222-4229.

37 Hokfelt T, Xu ZQ, Shi TJ, Holmberg K, Zhang X. Galanin in ascending systems. Focus on coexistence with 5-hydroxytryptamine and noradrenaline. Ann NY Acad Sci 1998; 863: 252-263.
38 Melander T, Hokfelt T, Rokaeus A, Cuello AC, Oertel WH, Verhofstad A, Goldstein M. Coexistence of galanin-like immunoreactivity with catecholamines, 5-hydroxytryptamine, GABA, and neuropeptides in the rat CNS. J Neurosci 1986; 6: 3640-3654.

39 Pieribone VA, Xu ZQ, Zhang X, Grillner S, Bartfai T, Hokfelt T. Galanin induces a hyperpolarization of norepinephrine-containing locus coereleus neurons in the brainstem slice. Neuroscience 1995; 64: $861-874$. 